\title{
A new Frontier for headache
}

\section{Stephen Silberstein*}

Jefferson Medical College, Thomas Jefferson University, Philadelphia, PA, USA

*Correspondence: stephen.silberstein@jefferson.edu

Headache ranks \#1 on the roster of pain complaints. It accounts for over 10 million physician visits annually (National Center for Health Statistics, 1979; Lipton et al., 1997). Relatively few headache sufferers receive appropriate diagnosis and adequate care. Migraine sufferers are the most dissatisfied patients; half of those who consult eventually stop seeking medical care for their headaches. Only $28 \%$ of migraine suffers say they are very satisfied with their usual treatment (Lipton et al., 1998; Lipton and Stewart, 1999). Migraine has major implications for the patient's job and for his or her family and social life (Von Korf et al., 1998; Hu et al., 1999). Migraine suffers experience significant disability, diminished quality of life, and lost workdays, with migraine accounting for over $\$ 13$ billion dollars a year because of missed workdays (Hu et al., 1999).

An estimated $18 \%$ of women and $6 \%$ of men suffer from migraine, but about half never receive a medical diagnosis (Stewart et al., 1992). There have been a number of advances in the diagnosis and treatment of migraine and great strides have been made in understanding its pathogenesis. Despite this, headache is still a neglected field. Very few academic headache centers exist, and those that do exist often have financial difficulties. Medical schools lack staff with expertise in headache disorders, as opposed to staff with expertise in other neurologic disorders, such as multiple sclerosis and Parkinson disease, which have less societal impact.

We need to improve and expand basic research (National Center for Health Statistics, 1979), improve and expand clinical research (Lipton and Stewart, 1999), establish ideal environments for translational research (Lipton et al., 1998), improve education of medical students, residents, and fellows (Lipton et al., 1998), extend the field by improving and creating standards of care (Hu et al., 1999), and establish a system that measures treatment outcomes, places headache at the forefront of academic medicine, and leads the initiative to individualize patient care.

In keeping with the goals and philosophy of the Frontiers Organization, we will promote a wide range of contributions to the field of headache, ranging from pathogenesis and pathophysiology to clinical approaches. We will create an on-line environment for interactions between scientists and clinicians that is crucial for the success of translational research. The complexity of headache disorders dictates a multidisciplinary approach. This encompasses neurology (evaluation and diagnosis) and psychology (psychotherapy and biofeedback). In addition, internal medicine (general health evaluation), anesthesia (interventional procedures), gynecology (hormonal replacement therapy), dentistry or oral surgery (TMJ diseases), otolaryngology (vertigo), psychiatry (physical/massage therapy), nutrition (nutritional adjustments), and mind-body medicine (yoga, meditation, deep-breathing exercise, guided imagery, progressive relaxation, tai chi) are useful and at times crucial adjuncts. We are interested in publishing in all of these fields. Frontiers in Headache will thus become not only a significant contributor to the most common approaches in the fight against headache, but will actually help push the boundaries of the field in directions that are seriously neglected and need to be developed urgently in order to conquer headache and related disorders.

\section{REFERENCES}

Hu, H. X., Markson, L. E., Lipton, R. B., Stewart, W. F., and Berger, M. C. (1999). Burden of migraine in the United States. Arch. Int. Med. 159, 813-818.

Lipton, R. B., and Stewart, W. F. (1999). Do dictor's know what migraine suffers want from treatment. Headache 39, S20-S26.

Lipton, R. B., Stewart, W. F., and Simon, D. (1998). Medical consultation for migraine: results from the American migraine Study. Headache 38, 87-96.

Lipton, R. B., Stewart, W. F., and Von Korf, M. (1997). Burden of migraine: societal costs and therapeutic opportunities. Neurology 48(Suppl. 3), S4-S9.

National Center for Health Statistics (1979). Vital and Health Statistics of the United States. D.H.E.W., PHS Publication No. 53. Advance Data. Hyattsville, MD: National Center for Health Statistics.

Stewart, W. F., Lipton, R. B., Celentano, D. D., and Reed, M. L. (1992). Prevalence of migraine in the United States. JAMA 267, 64-69.

Von Korf, M., Stewart, W. F., Simon, D., and Lipton, R. B. (1998). Migraine and reduced work performance. Neurology 50, 1741-1745.

Received: 26 August 2010; accepted: 28 September 2010; published online: 20 October 2010

Citation: Silberstein S (2010) A new Frontier for headache. Front. Neur. 1:135. doi: 10.3389/fneur.2010.00135

This article was submitted to Frontiers in Headache Medicine and Facial Pain, a specialty of Frontiers in Neurology.

Copyright (C) 2010 Silberstein. This is an open-access article subject to an exclusive license agreement between the authors and the Frontiers Research Foundation, which permits unrestricted use, distribution, and reproduction in any medium, provided the original authors and source are credited. 